\title{
A Relação Ciência-Indústria no Processo de Inovação: as ciências da vida em debate
}

José Wladimir Freitas da Fonseca*

\section{Introdução}

O objetivo deste artigo é contribuir ao debate da relação ciência-indústria, emitindo a hipótese de que os processos de valorização e de negociação dos conhecimentos, notadamente nas Ciências da Vida, repousam sobre a especificidade das ciências modernas que entram numa relação particular com a técnica, que por sua vez vem orientar as ciências modernas conferindo, assim, um sentido particular. Mostraremos que a penetração dos processos técnicos na construção dos savoirs constitui um lugar de passagem obrigatório na lógica que conduz da construção dos conhecimentos à sua industrialização. Portanto, na análise da relação específica que existe entre a ciência moderna e a técnica é que podemos encontrar um esclarecimento particular para uma relação que articula ciência-técnica-indústria. Propomos no quadro restrito deste artigo uma explicação alternativa que leva em conta o conjunto dos componentes desta relação.

\section{O estado dos discursos: uma constatação de fragilidade}

A maior parte das teorias consideram a firma como constituída por um dispositivo complexo cujo objetivo, entre outros, consiste em resolver problemas de informações. [Cohendet (1997); Fransman (1994)]. Em outro, Fransman mostra que as abordagens se diferenciam umas das outras em função da natureza e das especificidades dos problemas “ "informacionais" a resolver. Desta forma, a informação torna-se um problema transversal a todos os quadros conceituais, assim como uma variável sensível a partir da qual se posiciona a firma e que condiciona sua organização e, até mesmo, seu modo de coordenação. A utilização do conceito de informação não é novo e já foi utilizado anteriormente. De uma forma geral, as ciências e as técnicas são reduzidas e reconduzidas a um sistema de informação que tornase assim a variável privilegiada e atrás da qual se esconde a natureza e as funções das ciências e das técnicas.

$\mathrm{Na}$ realidade, o conceito de informação como variável que se substitui pelas ciências e pelas técnicas não é novo na literatura econômica. Com o fim dos anos setenta e os debates sobre as teorias do desenvolvimento, a idéia de transferências de tecnologia entre países desenvolvidos e países em vias de desenvolvimento é reconduzido a uma transferência de

\footnotetext{
* Professor do Departamento de Economia da Universidade Federal do Paraná (UFPR). Doutor pela Université de Toulouse I - França. Endereço Eletrônico: wladi@,ufpr.br
} 
informação entre as duas partes (Perrin, 1983). As técnicas de produção são aqui consideradas como sendo o conjunto das informações utilizadas pelos homens para transformar a matéria e organizar sua participação (no nível da oficina, de uma empresa, de um ramo industrial, de uma nação e entre nações). A partir de então, a transferência de conhecimento e/ou de tecnologia é considerada como um processo de Transmissão/Aquisição de informação que coloca em jogo os diferentes detentores e receptores destas informações. A informação, conforme Rosanvallon (1981) é, portanto, definida como um conjunto de atividades e um conjunto de conhecimentos retidos pelos agentes. A informação se inscreve com efeito, ao mesmo tempo, num quadro da atividade do informante e do informado e, a partir do momento que ela pertence ao informado torna-se um objeto de conhecimento que se integra a representação orientada das atividades dos agentes. A transferência de conhecimento ou de tecnologia torna-se então um problema de decodificação entre os atores em jogo nesta operação e cujo sucesso (ou fracasso) depende do grau de complexidade da operação. Insistimos sobre esta questão na medida em que esta acepção do conhecimento e da técnica (ou tecnologia), isto é, a redução destes dois elementos fundamentais da transferência, produz um certo número de conseqüências quanto à compreensão do fenômeno de transferência enquanto tal: não se trata mais com efeito de operar a compreensão de um dispositivo concernente à ciência e/ou a técnica, mas de descrever as melhores condições para transferir uma informação, a troca sendo a melhor possível para assegurar a transferência de direitos de propriedade.

A literatura dos dez últimos anos neste domínio não retoma nos mesmos termos e de forma sistemática esta abordagem do processo de transferência. A razão disso está principalmente no fato de que as variáveis ciências e técnicas não se deixaram fechar num tal esquema e que a invasão repentina e violenta das novas tecnologias ligadas ao desdobramento dos savoirs na indústria fez ressurgir na atualidade. A lógica da transferência não era mais concernente somente aos países desenvolvidos e aos países em vias de desenvolvimento, mas é este conjunto de economias desenvolvidas que foi confrontado a este problema. A importância dos savoirs e do savoir-faire no processo de desenvolvimento industrial, em particular para responder aos problemas de emprego, o fenômeno de "mundialização" da economia e da concorrência, que a ela é fixada, impuseram aos diferentes atores da economia pensar sobre o problema em termos de inovação técnica e de valorização dos savoirs e de savoirfaire. A ciência e a técnica, então, somente podiam voltar na frente da cena e portanto ser pensadas num processo no qual é necessário liberar o sentido e a lógica. É precisamente 
este estado dos discursos que desejamos analisar aqui a fim de ver em que medida a lógica do processo de inovação e de transferência científica e técnica são explicitadas (ou não).

\subsection{A relação Ciência/Indústria: as dificuldades de uma problemática}

\section{integrada}

Os desenvolvimentos recentes no domínio teórico orientaram as pesquisas sobre as características principais da relação Pesquisa/Indústria, com a ciência ou o conhecimento tornando-se, então, uma variável da parte inteira da análise econômica do processo de inovação. Colocando a questão de saber se a teoria econômica tinha necessidade de uma nova economia da ciência, (Callon e Foray - 1997) o debate prolonga as proposições fundadoras de Dasgupta e David (1994) a fim de renovar e de rever as problemáticas já antigas, aquelas que haviam sido iniciadas por Nelson (1959) e Arrow (1962). Estes novos desenvolvimentos vão encontrar, notadamente com as abordagens neo-schumpeterianas e evolucionistas, um novo eco, com o acento sendo colocado sobre as instituições inovadoras compreendidas na relação Ciência-Indústria. O pesquisador-empresário torna-se o objeto de todas as atenções (QuéréRavix - 1995 e 1997), pois permite colocar à frente as dificuldades da análise econômica para integrar nas suas construções teóricas a atividade econômica. Podemos então distinguir duas orientações teóricas bem específicas, uma se interrogando sobre a importância e o papel da ciência nesta relação, e a outra, antes de tudo, com o acento sobre os aspectos industriais da inovação e suas condições.

a) A relação Ciência/Indústria versus ciência

Como constata De Bandt (1997), "la science a été l'objet de recherche depuis pas mal de temps, mais pas en science économique",e é certamente para remediar esta carência que os economistas tentaram tratar o problema da endogeneização da variável ciência no pensamento e na análise econômica. A partir de então, o problema da inovação e das transferências de tecnologia são abordados do ponto de vista do papel da ciência num tal processo. Como afirma ForayLundvall (1997), trata-se "d'équiper les savoirs nouveaux" das qualidades particulares que teriam como conseqüência de "les faire ressembler un peu plus" aos outros bens correntemente produzidos pelo sistema produtivo. Ademais, isso permitiria " faciliter les opérations de transfert et d'échanges" mas também "d'accès et de recherche": facilitar as trocas, constitui bem um fim em si mesmo para o economista. Mas esta forma de abordar o problema não é simplesmente utilitária, isto é, o único objetivo para levar em conta o processo de transferência e de inovação. Pavit (1992) defende a tese, muito em geral e não demonstrada, que a ciência universitária, isto é, as atividades de pesquisa, de formação conduzidas pela ajuda dos fundos 
públicos, é um fator essencial da tecnologia industrial, isto é, são as atividades de produção e de pesquisa privada que se conduzem pela ajuda dos fundos públicos e a seus benefícios próprios. Ele nota igualmente que os resultados da pesquisa privada sob a única forma de uma produção de informações codificadas, úteis e publicadas é excessivamente restrita, pois ela poderia ter conseqüências negativas nas escolhas em matéria de políticas públicas de apoio a pesquisa. Neste sentido, o problema da transferência da ciência para a tecnologia e depois para a indústria se caracteriza portanto da seguinte forma:

i) A intensidade das transferências varia em função dos setores e depende da importância da pesquisa no setor; por exemplo, estas transferências são relativamente intensas nas ciências do ser vivo e muito frágil no domínio dos transportes;

ii) A incidência da pesquisa sobre a tecnologia varia com o tempo, tecnologia devendo chamar a engenharia da produção; isso supõe o acesso aos métodos de pesquisa, aos instrumentos e aos conhecimentos não codificados;

iii) As transferências de conhecimento tornam-se um negócio de indivíduos, de contatos pessoais, de deslocamentos e da participação das redes.

O autor conclui desejando não ver a ciência (ou a tecnologia?) ser reduzida a uma simples capacidade de produzir informações facilmente transmissíveis e aplicáveis.

O ponto de vista desenvolvido por De Bandt nos parece interessante e merece ser detido. A abordagem parece tanto mais interessante para nosso propósito do que as palavras chaves do artigo que enviam o leitor à ciência, à produção de conhecimento e às relações pesquisa/empresa. O conteúdo desenvolvido se articula em torno de duas idéias centrais:

- de uma parte a ciência é distanciada em relação a realidade do fazer e tem podido se organizar em um sistema autônomo capaz de definir seus próprios critérios de referência.

- de outra parte, a atividade científica, isto é a produção de conhecimentos, vai perder seu estatuto particular. Vivemos uma situação de transição, pois passamos de uma situação na qual o homem é um ser pensante a uma situação onde o homem é um ser que faz, isto é, alguém que age sobre a natureza e produz objetos técnicos. Nestas condições, o estatuto do conhecimento se modifica: o conhecimento é de fato fundamentalmente ligado à ação, ele é inseparável da ação.

Assim, tudo isso nos conduz ao fato de que, enquanto a produção de conhecimento científica tende a perder sua identidade, a produção de conhecimento útil tende ao inverso, a se multiplicar e, sobretudo, no quadro das lógicas de solução de problemas (problem solving), e compreendido no quadro do sistema produtivo. Nestas transformações em curso, as 
tecnologias desempenham evidentemente um papel importante na difusão dos conhecimentos e seus impactos sobre a organização das atividades econômicas é bem determinante. $\mathrm{O}$ autor chega assim a uma conclusão, que conforme ele exprime é um movimento contraditório, cujos termos são os seguintes: no movimento de transição, esta difusão comporta um duplo movimento de causa/transformação. Pela evidência, o interesse repentino dos economistas que teria como objetivo rejeitar os novos paradigmas da economia da informação ou do conhecimento.

b) A relação Ciência/Indústria versus indústria

O ponto de vista precedente se desenvolveu a partir de uma abordagem da relação Ciência/Indústria fundada sobre o papel predominante da ciência, que trata-se da visão de Pavitt de insistir sobre a ciência ou, da visão de De Bandt de uma certa rediscussão da ciência que qualificaremos de clássica. Desejamos abordar aqui o problema sob um outro ângulo, que coloca mais especificamente a importância do aspecto industrial desta relação e mais particularmente insistindo sobre a relação pesquisador-empresário (Quéré-Ravix - 1997a e b). Os autores não procuram aqui integrar a atividade científica enquanto que variável agindo diretamente sobre a atividade econômica ou como uma atividade econômica particular, mas analisar a forma como ela participa na ação dos agentes privados nas suas atividades industriais. Não se trata portanto de justificar a pertinência da economia da ciência enquanto objeto de análise mas de reter a inovação como vetor que articula a relação pesquisador/empresário. Os autores (Quéré-Ravix - 1997a) mostram numa abordagem crítica, com a qual partilhamos, que a oposição habitual entre conhecimentos codificados, isto é, os conhecimentos considerados como informações transferíveis pela troca e os conhecimentos tácitos, isto é, um bem específico que fica dificilmente transferível, pois ele não pode necessariamente fazer o objeto de transição. A primeira abordagem não pode conciliar um lugar suficiente no processo pelo qual o conhecimento continua a crescer no tempo e se desenvolver. Posiciona-se, então, na problemática de determinação das condições de otimização dos agentes individuais no quadro da aquisição e de valorização dos conhecimentos disponíveis, onde ficam os bens-de-informação caracterizados pelas condições de troca e pela determinação dos preços que eles resultam.

A abordagem evolucionista que constitui o segundo ponto de vista parte de uma definição diferente do conhecimento que tem a tendência de tornar-se complexa levando em conta indistintamente os conhecimentos codificados e tácitos, empíricos, pragmáticos ou mais abstratos, individuais ou coletivos. A partir de então, a ciência (ou o conhecimento) é 
percebida sob um duplo ponto de vista: de uma parte ela constitui um recurso para a firma, é analisada como tal e ratifica a idéia de uma endogeneização do conhecimento enquanto que um input privilegiado na dinâmica de inovação; de outra parte, é concebida como uma contribuição em termos de competência, isto é, como a atitude para explorar e desenvolver o conjunto das oportunidades que caracteriza um sistema de produção. A este respeito, os autores notam com pertinência o interesse de sublinhar as diferenças concernentes ao conceito de conhecimento: enquanto que para alguns (os neoclássicos e assimilados), trata-se de um problema de acesso ao conhecimento, restando exógeno ao modelo, ele deve necessariamente ser tratado como uma transferência de informações; para outros (os evolucionistas), numa preocupação de realismo e para evacuar o conceito de bem-deinformação, a questão que se coloca é aquela da natureza do conhecimento, dissociando assim o aspecto codificado do aspecto específico. A possível saída para uma tal oposição reside, portanto, em parte no estatuto do conhecer ao qual fazem referência os autores e, de outra parte, na relação pesquisa-indústria que não pode constituir uma simples transferência de conhecimento, mas um lugar de arranjos institucionais cujo objetivo é a criação e a utilização do saber. A partir de então, o pesquisador-empresário, híbrido institucional da ciência e da indústria se coloca no centro do processo não somente da dinâmica industrial da inovação, mas torna-se também o arquétipo do inovador-criador da empresa. Ele escolhe então as opções conjunturais, de preferência as opções possíveis que a ele são fornecidas e é mais ainda o caminho da atitude que interessa aos nossos autores do que o resultado da visão processual da inovação. Assim, a abordagem em termos de pesquisador-empresário apresenta portanto um duplo interesse: de uma parte, ela está na intersecção da pesquisa e da indústria e permite tratar o conhecimento não como transferência de informação da esfera científica e técnica à esfera industrial, mas de outro modo; de outra parte, se o problema da economia do conhecimento não se resolve através do prisma distorcido da difusão de bens-de-informação, o estudo do pesquisador-empresário no processo de inovação-criação é particularmente interessante. Com efeito, trata-se de suas competências individuais em termos técnicos ou em termos de gestão, de sua atitude para organizar a informação na qual concerne o processo de inovação que ele escolhe para empregar ou, trata-se do ambiente no qual o pesquisadorempresário intervêm, sendo a densidade institucional do dispositivo um fator importante, até mesmo determinante.

Amendola e Gaffard (1988) propõem uma reviravolta na análise do processo de inovação, cuja problemática nos parece significativa. A importância recente adquirida pela 
ciência moderna nos desenvolvimentos das últimas tecnologias conduz a modificações características do sistema produtivo e sua forma de integrar os processos de inovação. A tecnologia, que não se confunde aqui com as ciências, é compreendida como a capacidade de um ambiente dado - meio, sistema, economia...- a conceber e a fazer existir problemas e soluções produtivas, e esta atitude depende dos recursos específicos que exprimem a importância do ambiente no qual elas aparecem (p.23). Isso significa que existe uma história particular destas diferentes tecnologias e somente os recursos humanos que são formados por tal processo são o suporte desta história. Com efeito, estes novos processos de pesquisa no domínio técnico permitem aos seus desenvolvimentos adquirirem novas aprendizagens por acumulação de experiência; isto dá lugar a novos domínios técnicos e a novas capacidades que permitem situar sobre o terreno da produção. Esta passagem à economia exprime a faculdade da ciência e da técnica de ser utilizada industrialmente. O processo é portanto interpretado como um processo de aprendizagem (no sentido evolucionista do termo) que foi iniciado pelas escolhas inovadoras e, portanto, o resultado reside na aquisição de novas capacidades, isto é, a aparição de novos recursos específicos em trabalho. Estes novos recursos fazem, a seu tempo, aparecer novas configurações produtivas e portanto novas tecnologias. Enquanto o processo tradicional consiste em colocar em relação causal tecnologia-processo de inovação, a descrição dos autores conduz a uma reviravolta que subordina a tecnologia ao processo de inovação: "la technologie, d'un point de vue analytique, apparaît alors comme un résultat du processus d'innovation et non comme une condition préalable de cellui-ci"(p.24). Isto pois, as mudanças qualitativas intervêm nos recursos em trabalho e tornam possível o desenvolvimento, novas possibilidades de produção resultam de uma aprendizagem que é o resultado de experiências adquiridas que permitem por sua vez desenvolver "noveau sentier", o processo de inovação somente podendo ser seqüencial. Um tal processo de aprendizagem que se traduz por uma renovação constante das técnicas empregadas é a origem de novos processos produtivos permitindo assim uma sorte de flexibilidade (isto é " permite a possibilidade de mudança de direção" tecnológica) que autoriza o desenvolvimento da gama de seqüências possíveis a cada passo sucessivo. Conforme os autores, "l'interprétation proposée éclaire des aspects importants du processus d'innovation et elle constitue la base d'une explication des processus de changement". Todavia, não se vê em que uma simples mudança de perspectiva pode modificar as coisas: seria necessário para isso inverter a relação de causalidade demonstrando o bem fundado de uma tal tentativa, o que não é o caso, aos nossos olhos. Temos, ao contrário, a impressão de nos encontrarmos face a alternativa da galinha e do ovo: isto é, a técnica que faz a inovação ou a inovação que 
faz a técnica? Quanto ao conteúdo da relação e a natureza do mecanismo, avançamos muito pouco.

A apresentação feita, mesmo que não seja perfeitamente exaustiva, permite ver em quais termos a questão da inovação, das relações ciência/indústria é colocada. Convém agora apreciar uma crítica que ela suscita.

\subsection{Entre ciência e técnica: um lugar de confusão}

O tratamento da questão da inovação e das transferências tal como é colocada se divide portanto em duas posições que se opõem e que concernem ao estatuto do conceito de conhecimento: seja o conhecimento que toma a forma de um bem de informação trocável e transferível, como qualquer outro bem, seja quando se trata de um conhecimento tácito que se reveste de características particulares mas que é sobretudo dificilmente transferível. Esta oposição dual nos parece contestável e justifica um certo número de críticas que podem servir de base para uma reformulação teórica do problema. Estas críticas podem se resumir da seguinte forma:

1 - Aparece na leitura que quase a totalidade das proposições analíticas que examinamos adotam um posicionamento, antes de tudo descritivo, que conta o desencadeamento de um fenômeno observável sem, no entanto, explicá-lo. Esta descrição tem geralmente como objetivo validar o quadro prévio escolhido estabelecendo uma adequação formal. Seja Dasgupta-David (1986) com a teoria da agência, da abordagem evolucionista, das concepções institucionalistas, o objetivo procurado consiste em (com exceção de Quéré-Ravix - 1997a e b) estabelecer a posteriori uma adequação entre o quadro teórico prévio e o fenômeno observado. O inconveniente de tal método reside no fato de que os mecanismos são tomados não eles mesmos, isto é, em função do objetivo de validação dos quadros conceituais. De sorte que, se o fenômeno é apreendido em uma certa lógica de desencadeamento, ele fica insuficientemente explicado na sua totalidade, notadamente quanto às relações de causalidade.

2 - O conjunto dos textos, os quais fazemos referência aqui, apresenta um caráter comum: conhecimento, ciência, tecnologia e técnica são utilizados indistintamente e reenvia somente ao processo de transferência de tal forma que os autores colocam a frente um processo o qual eles não levam em conta e sem jamais explicitar do que ele se trata. Certos, compreendemos perfeitamente que se pode englobar, sob o termo de conhecimento, não somente os savoirs mas também os savoir-faire. Após tudo, historicamente, a técnica precede a ciência, e uma invenção técnica é tão importante quanto uma descoberta científica: o que seria 
a biologia molecular sem a contribuição do microscópio eletrônico. Todavia, se a descoberta científica e a invenção técnica não somente co-existem e se interpenetram, não se pode sobretudo confundi-las: a ciência tem como objetivo responder a questão "porquê?" enquanto que a técnica resolve a questão "como?". Ora, é incontestável que o conjunto dos textos analisados assimila ciência e técnica a ponto de fazer uma única e mesma variável, cada uma perdendo uma parte da espessura ontológica que a caracteriza.

3 - Enfim, as concepções econômicas do conhecimento ignoram geralmente o que outros campos disciplinares forneceram à compreensão deste fenômeno fundamental, mesmo se tratando das contribuições da filosofia e/ou da sociologia eles têm um resultado estranhamente pobre neste domínio. Assim é possível perceber que a relação pesquisaindústria não é uma simples transferência de conhecimento.

Propomos portanto aqui, desenvolver uma abordagem que leva em conta estas observações, notadamente tentando compreender e dar um sentido ao conceito de conhecimento.

\section{Ciência e técnica: sentido de uma relação no domínio das ciências da vida}

Com Descartes, a ciência e a técnica entram numa relação específica e, a fim de melhor compreender estas inter-relações, diremos que a técnica "percole" a ciência e vem modificar o curso orientando-a. Atrás da idéia de percolação aparece o fenômeno de penetração mas, sobretudo, a idéia de transformação, de uma orientação simultânea do meio no qual ela se produz de forma que no caso da relação ciência/técnica, essa vai modificar as orientações que toma a ciência, desempenhando assim um papel de transformação no seu devir e no sentido deste devir. Assim, se a concepção do conhecer se liga sempre às regras da pesquisa da verdade e da universalidade, a ciência não poderia ser percebida fora das condições nas quais ela se desdobra e das contingências que presidem à sua elaboração.

Sem entrar no detalhe da história da biologia, podemos afirmar que é com Watson e Crick que a convergência entre composição química da nucleína e a transmissão hereditária dos caracteres tornam-se possíveis. A partir desta data, o objeto de conhecimento (o gene e seus modos de expressão) tornam-se progressivamente um objeto técnico, isto é, um lugar de manipulação no sentido de Descartes. O nível molecular da análise se substitui a uma escala que poderíamos qualificar de macromolecular. Trata-se de recortar as macromoléculas a fim de extrair seqüências, tendo um sentido do ponto de vista da expressão fenotípica, através da produção de proteínas. Tal recorte necessita previamente da obtenção de um ADN relativamente puro e não degradado, o recurso às ferramentas apropriadas para conduzir bem 
este recorte (enzimas de restrição), para isolar, identificar e recolher os fragmentos assim obtidos, para analisar seus tamanhos, suas composições e seus papéis na biosíntese protéica sendo indispensável. A perda progressiva de referência em relação a um referencial epistêmico se reencontra nesta sorte de deriva semântica que coloca sob a mesma terminologia (o gene) duas entidades bem distintas:

- a técnica tornando-se objeto e meio do conhecimento, se automatiza e se remarca definitivamente de sua base epistêmica. As técnicas de seqüenciamento do genoma não constituem um meio de elaborar uma resposta aos questionamentos da genética neomendeliana, de indentificar a base material do gene mendeliano. Esta, desvenda uma tendência à automatização da biologia molecular, fenômeno no qual, a técnica, ao mesmo tempo questiona e responde;

- o objeto de conhecimento (a seqüência do $\mathrm{ADN}$ ) coincide com a produção de proteínas e torna-se um objeto técnico entre as mãos do experimentador, isto é, mediador entre o homem e a natureza.

Da introdução de uma seqüência de ADN no cromossomo de uma célula, a fim de fazê-la sintetizar uma ou várias proteínas, à modificação de certos caracteres de vegetais ou de animais a fim de aumentar um potencial de produção, vemos identificar-se aí o surgimento do que se convencionou chamar de engenharia genética. A biologia molecular enquanto projeto científico em vias de realização (cuja cartografia e a interpretação completa do genoma dos organismos vivos constituiria o símbolo deste resultado), representa igualmente uma sorte de ponto de partida de um desenho tecniciano: a engenharia genética. Mas esta passagem concretiza o prolongamento lógico de um processo histórico que reenvia à tecnicização dos conhecimentos. A construção epistêmica cede o lugar a esta lógica tecniciana que se encarna na engenharia genética no ponto em que o argumento tecniciano torna-se a justificação no programa de pesquisa em biologia molecular: o objeto de conhecimento se funde, assim, em uma ferramenta. Uma seqüência de ADN, uma vez identificada suas_funções, torna-se o meio de produzir uma substância ou de exprimir um caractere num organismo. Ela ultrapassa assim, a fronteira cada vez mais tênue entre a coisa para conhecer e o meio de agir sobre a natureza. A apropriação desta ferramenta e sua comercialização se encontram diretamente induzidas pela materialização do vivente que se opera pela ausência de um retorno sobre o que esta matéria tem de singular. Uma bactéria geneticamente modificada a fim de produzir uma substância farmacêutica representa, de um ponto de vista industrial, uma ferramenta de produção e seu caráter de vivente desaparece tornando-se a usina química que ela representa. 


\subsection{A técnica como lugar de passagem obrigatória do processo industrial.}

A ferramenta concretiza o prolongamento do gesto e este prolongamento toma o trabalho como intermediário. Ora, todo trabalho é criação de valor (no sentido econômico do termo), o que confere ipso facto à ferramenta um lugar eminentemente econômico. A partir do momento onde a fabricação de ferramentas e, por extensão, de máquinas, se insere num processo de criação de riquezas, a tendência à tecnicização dos conhecimentos deve ser acompanhada de sua entrada na esfera econômica. Ora, se a inserção dos resultados de conhecimentos nos circuitos econômicos se efetiva, isso significa que previamente estes resultados suportaram uma transformação conduzindo-os a se ornamentar das propriedades aferentes aos bens econômicos (enquanto produto de consumo ou processo de produção), e tal transformação não pode se realizar a não ser por uma tecnicização destes conhecimentos.

A tecnicização dos conhecimentos se encontra na origem de uma reaproximação (ver mesmo de uma confusão) entre os programas das instituições de pesquisa pública e aqueles da pesquisa conduzidas no seio das indústrias. Esta convergência e as transferências sempre mais importantes que se operam entre a pesquisa pública e privada representam uma manifestação da passagem da tecnicização à industrialização dos conhecimentos. Avançamos na idéia de que existe uma reaproximação progressiva e inexorável entre os temas desenvolvidos pela pesquisa pública e aqueles das firmas industriais. A tecnicização dos programas e suas finalizações de um lado, o desenvolvimento de savoirs industriais cada vez mais elaborados de outro, marcam esta reaproximação tendencial. Mas, este movimento somente traduz com efeito um processo mais profundo que se apóia sobre a tecnicização dos conhecimentos desenvolvidos anteriormente. Para evocar simplesmente este fenômeno, diremos que a convergência temática das pesquisas públicas e privadas nas "ciências do ser vivo" se opera em torno de uma lógica tecniciana, mais próxima da vocação industrial do que a missão do serviço público e, esta observação funda certamente o mal-estar que passa atualmente a pesquisa pública e o sentimento de que ela se curva cada vez mais diante das pressões e aos imperativos econômicos. A biologia molecular como exemplo se inscreve no prolongamento de uma tecnicização dos conhecimentos do vivente e, a partir de um certo nível, esta impregnação pela técnica faz oscilar o objeto de conhecimento no conjunto dos bens econômicos e esta oscilação está no centro do processo de inovação ou de transferência.

Assim, o movimento de tecnicização dos conhecimentos no qual fundamos a lógica histórica nas ciências do ser vivo se opera, a montante, em detrimento do campo epistêmico e chega a jusante sobre formas cada vez mais tecnicizadas de produções científicas. As "técnicas 
do ser vivo" que conduzem ao seqüenciamento do genoma transformam esta seqüência num instrumento destinado a um fim, isto é, mercadorias nos domínios farmacêuticos, meioambiente ou agro-alimentares. Encontramos, portanto, numa situação de captura pela indústria. A técnica favorece a industrialização e a biologia molecular tende então à engenharia genética. É esta transição que caracteriza o movimento de "percolação" que tínhamos definido anteriormente e ela manifesta a dimensão econômica do processo assim como seu caráter inevitável. O processo de inovação caro aos economistas (o processo de Pesquisa/Desenvolvimento) não é outra coisa senão esta longa história que nos conduz dos savoirs acadêmicos nas formas mercantis específicas à esfera de circulação de mercadoria.

\section{Conclusão}

As idéias apresentadas aqui revelam uma lógica repleta de sentido, mas apenas um dos elementos do quebra-cabeça. As idéias mostram que o problema da transferência depende então da possibilidade da passagem da descoberta científica à intervenção do objeto técnico que constitui a condição sine qua non da industrialização e da facilidade e velocidade com a qual esta transferência se fará, pois ela depende:

- de uma parte, do distanciamento da descoberta científica e da sua configuração econômica: quanto mais a descoberta científica é abstrata e distanciada das condições de aplicação, mais a esfera econômica é distanciada;

- de outra parte, da importância dos processos técnicos que acompanham o trabalho científico. 